VARNA

UNIVERSITY OF

MANAGEMENT

\section{European Journal of Tourism Research \\ http://ejtr.vumk.eu}

\title{
Dixit, S. K. (Ed.) (2020) Tourism in Asian Cities. London: Routledge. Hardback. 330 pages. ISBN 9780367210021
}

\author{
Reviewed by \\ Kyungjae Jang ${ }^{1 *}$
}
${ }^{1}$ Graduate School of Humanities and Social Sciences, Hiroshima University, Japan, e-mail: jang@hiroshima-u.ac.jp ${ }^{*}$ Corresponding author

Citation: Jang, K. (2022). Book review of Dixit, S. K. (Ed.) (2020) Tourism in Asian Cities. London: Routledge. ISBN 9780367210021. European Journal of Tourism Research 31, 3121. 
Tourism in Asian Cities is part of Routledge's Contemporary Geographies of Leisure, Tourism and Mobility book series, which aims to explore and communicate the intersections and relations between leisure, tourism, and human mobility within the social sciences. The book is published at a critical and timely point in the context of the rapid growth of urbanisation and urban tourism in Asia. In particular, as emphasised in the text, the current COVID-19 crisis provides an opportunity to restructure while taking a break in all tourism fields. The book appears at the right time to contribute to this point.

In Tourism in Asian Cities, the authors explore the characteristics and complexity of urban tourism in Asia by contrasting the differences in the possibility and degree of transfer of urban tourism, a concept that has been mainly discussed in the Western context, to the Asian environment. Urbanisation in Asia is progressing at a rapid pace, accompanied, on the one hand, by vibrant urban tourism and, on the other, many emerging problems. Geographically, this book covers almost all Asian regions, from Korea and China in East Asia to India and Sri Lanka in South Asia. Researchers and practitioners in various academic disciplines, such as geography, business administration, anthropology, and marketing, illuminate cases from various perspectives.

This book is divided into three parts and 16 chapters. Part 1, Urban tourism Precincts in Asia: An Introduction, consists of five chapters. Chapter 1 serves as an introduction to the entire book and explains the overall history and framework of urban tourism, its attractiveness and objects, and its dimensions in the modern world. The chapter connects urban tourism and Asia, as the core topic of this book, and discusses the challenges that Asia's urban tourism faces and needs to be addressed. Chapters 2 to 3 describe urbanisation and urban tourism in Sri Lanka and member countries of the Association of Southeast Asian Nations (ASEAN). The urban tourism development model of Sri Lanka is introduced in Chapter 2, which especially emphasises the importance of urban resilience to ensure sustainability in the development of tourism in cities. Chapter 3 compares the urbanisation patterns, differences, and tourism development of cities in ASEAN, a unit that transcends the national level. Chapters 4 and 5 deal with detailed city tourism on a smaller scale. Chapter 4 presents an analysis of the dynamic process in which the city of Tianjin, in China, was developed by Westerners, preserved as a cultural heritage, and re-created through reinterpretation as concessions for foreigners. This chapter focuses on creative tourism. Moving to India, Chapter 5 similarly deals with cultural heritage tourism but also discusses the combination of tangible and intangible heritage and regional revitalisation.

Part 2, Management and Marketing of Asian Cities, dedicates six chapters to the concepts of placemaking, promotion, branding, and marketing in Asian urban tourism. First, Chapter 6 discusses how 'building archaeology' contributes to city tourism promotion for Kolkata, India. Whereas Chapter 5 analyses the consciousness of cultural heritage tourists, Chapter 6 is on how to create a building based on historical data, and this is the point where Part 2 is different from the previous part. Chapter 7 , which shines the spotlight on Phuket, Thailand's tourist island, discusses how to overcome the negative impact of natural disasters on the tourism and hospitality industries and further engage the community in tourism development and tourism in the region. Next, the tourism challenges facing Ulaanbaatar, Mongolia, are addressed in Chapter 8. A form of marketing that combines the image of steppesincluding their nomads and the hospitality unique to nomads - with city tourism, highlighting the rapid economic development of the urban area, shows the potential of unique urban tourism. Chapter 9 explains the Disneyization and thematic tourism in Cambodia. This phenomenon can be seen to create variety and difference, and, the chapter posits, Disneyization can enable tourist cities to move forward through appropriate balance. Chapter 10 analyses Hong Kong's food trucks as a new resource for city tourism and food tourism. A food truck is a restaurant with a unique and innovative concept that symbolises Hong Kong and the city. This chapter argues, via a balanced analysis anchored in tourism 
development and promotion, that the positive and negative aspects of food trucks provide authentic experiences. Chapter 11 connects the tourism and religious aspects of Asian cities from a macro perspective. In a situation where it becomes difficult to divide the dichotomy between pilgrims and tourists in a post-secular society, the so-called threefold model is presented to explain the authenticity of religious tourism, the motivation of tourists, and the dynamic tourism space. Chapter 12 closes Part 2 by returning to Indian cities and 'smart tourism'. After extracting the factors of success in large cities in other countries, this chapter proposes a way for Indian cities to be competitive as targets for smart tourism.

Finally, Part 3, Emerging Paradigms of Asian City, extrapolates in four chapters the challenges facing Asia's urban tourism from a multi-layered and multi-faceted perspective. Chapter 13 discusses the complex process of place-making in the re-creation of space for tourism consumption, targeting Gamcheon Culture Village in Busan, Korea. Through the paradox that appears in the conflict and compromise of different stakeholders and the appropriation and ownership of space, Chapter 13 emphasises the necessity of creating a complex but meaningful place that must be rendered with the cooperation of the local community. Chapter 14 analyses 'overtourism', the most pressing issue in global tourism before the COVID-19 pandemic. The chapter discusses the economic, sociocultural, and environmental impacts of overtourism, and presents the ${ }_{5} \mathrm{D}$ model for overcoming overtourism: deseasonalisation, decongestion, decentralisation, diversification, and the so-called deluxe tourism. Chapter 15 discusses visitor experiences using augmented and virtual reality for cultural heritage sites in Delhi, India. Unlike the two previous chapters on heritage tourism in India, this chapter offers a challenging perspective on how new technologies can be used to co-create cultural heritage values. Chapter 16 deals with the diversity and transformation of Macau tourism, particularly dissecting the conflicts, compromises, and challenges that appear in the development of tourism using local resources. The chapter is set in Macau that stands at a crossroads as it attempts to revitalise the local economy in various ways that account for its gaming base.

In summary, this book provides a rich and diverse approach to urban tourism in Asia. It is an important book that brings together themes ranging from cultural heritage tourism, food tourism, and religious tourism, to redevelopment in Asian cities. A limitation of the book is that it needs to integrate the insights and organise the comprehensive characteristics, and provide deeper analyses of Asian city tourism, particularly after the COVID-19 situation. The book serves professional researchers interested in city tourism, tourism administrators and industry practitioners, and undergraduate-level students learning tourism. This book invites readers to consider Asian city tourism comprehensively by including current problems faced and proposing insightful solutions.

Received: 06/09/2021

Accepted: 08/o9/2021

Coordinating editor: Stanislav Ivanov 